\title{
Knockdown of Serum- and Glucocorticoid-Regulated Kinase 1 Enhances Cisplatin Sensitivity of Gastric Cancer Through Suppressing the Nuclear Factor Kappa-B Signaling Pathway
}

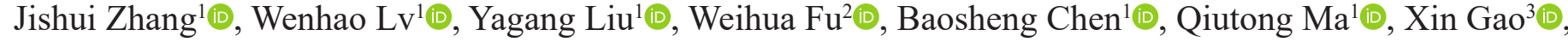 \\ Xiuxia Cui ${ }^{4}$
}

\author{
${ }^{1}$ The Second Department of General Surgery, Cangzhou Central Hospital, Cangzhou, Hebei, China \\ ${ }^{2}$ Department of General Surgery, Tianjin Medical University General Hospital, Tianjin, China \\ ${ }^{3}$ Department of Radiotherapy, Cangzhou Central Hospital, Cangzhou, Hebei, China \\ ${ }^{4}$ Department of Nuclear Medicine, Cangzhou Central Hospital, Cangzhou, Hebei, China
}

Background: Previous studies have published the promoting effect of serum and glucocorticoid-regulated kinase 1 (SGK1) in various malignant tumors. However, whether SGK1 promotes gastric cancer remains a mystery.

Aims: To clarify the function of SGK1 in gastric cancer and its potential regulatory mechanism.

Study Design: Cell culture study.

Methods: The SGK1-silenced model was generated in two gastric cancer cell lines and further evaluated their malignant behavior and susceptibility to cisplatin. The interaction between miR-15a-5p and SGK1 was evaluated by the luciferase reporter assay. The knockdown efficiency of SGK1 was confirmed by RT- qPCR and Western blot assays. Cell proliferation rate was assessed with CCK-8 assay, and flow cytometry was used to determine cell cycle progression and apoptosis. Results: Western blot data displayed an elevated level of SGK1 in gastric cancer cell lines. Functionally, SGK1 deficiency suppressed gastric cancer cell proliferation $(P<.01)$ by acting on cell-cycle progression.
Moreover, SGK1 deficiency suppressed cell invasion and migration of gastric cancer cells $(P<.01)$. Further, the silencing of SGK1 obviously suppressed cell proliferation and induced apoptosis of the cells after cisplatin treatment $(P<.01)$, indicating that SGK1 deficiency facilitated the chemosensitivity of these 2 gastric cancer cell lines to cisplatin. Mechanically, downregulation of SGK1 repressed the cytoplasm-to-nucleus translocation of NF-кB p65. Interestingly, we found that miR-15a-5p binds to the 3'UTR of SGK1, which was confirmed using luciferase activity assay $(P<.05)$. Moreover, the data suggested that SGK1 reversed the suppression effect of miR-15a-5p on gastric cancer cell migration $(P<.01)$.

Conclusion: Loss of SGK1 suppresses the malignant behavior of gastric cancer cells and increases cisplatin sensitivity by restraining the $\mathrm{NF}-\kappa \mathrm{B}$ signaling pathway. Moreover, SGK1 may exert an inhibitory effect in gastric cancer by being targeted by miR-15a-5p. Therefore, SGK1 may be a prospective target for future gastric cancer therapy.

\section{INTRODUCTION}

Gastric cancer has a high incidence and poor prognosis, and ranks third in contributing to cancer death in Asia. ${ }^{1}$ In recent years, the leading cause of failure for gastric cancer treatment is the presence of drug resistance in gastric cancer, imposing a huge economic burden on patients and the healthcare system. ${ }^{2-4}$ Therefore, it is urgent to search for potential molecular targets to improve the chemotherapy sensitivity of gastric cancer cells, gradually improving the therapeutic effect of gastric cancer treatment.
Previous researches have indicated that serum- and glucocorticoid-regulated kinase 1 (SGK1) plays a carcinogenic role in the development of a large number of cancers, such as colorectal cancer, ${ }^{5}$ prostate cancer, ${ }^{6}$ lung adenocarcinoma, ${ }^{5}$ etc. Additionally, recent research has found that SGK1 is implicated in the drug resistance of several cancer cells. For example, knockdown of SGK1 can reduce doxorubicin resistance in colorectal cancer cells. ${ }^{7}$ The SGK1-inhibitor SI113 inhibits cancer cell proliferation and offsets the blooming of paclitaxel resistance in ovarian cancer

Corresponding author: Jishui Zhang, The Second Department of General Surgery, Cangzhou Central Hospital, Cangzhou, Hebei, China e-mail: jishui_z1980@163.com

Received: April 21, 2021 Accepted: July 29, 2021 Available Online Date: September 29, 2021 • DOI: 10.5152/balkanmedj.2021.21114

Available at www.balkanmedicaljournal.org

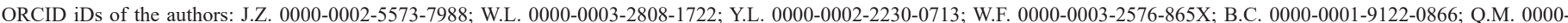
0002-3865-2827; X.G. 0000-0003-3441-655X; X.C. 0000-0003-3035-0469.

Cite this article as:

Zhang J, Lv W, Liu Y, et al. Knockdown of serum- and glucocorticoid-regulated kinase 1 enhances cisplatin sensitivity of gastric cancer through suppressing the nuclear factor kappa-B signaling pathway. Balkan Med J.; 2021; 38(6):331-340.

Copyright@Author(s)-Available online at http://balkanmedicaljournal.org/ 
cells. ${ }^{8}$ Importantly, an existing study has shown that SGK1 is significantly elevated in gastric cancer tissues, which is involved in the differentiation of Th2 and Th17 in the tumor microenvironment of gastric cancer. ${ }^{9}$ Nevertheless, the function and mechanism of SGK1 on gastric cancer are still unclear.

$\mathrm{NF}-\kappa \mathrm{B}$, which is highly expressed in various cancers, sparks tumor growth via stimulating the production of angiogenesis factors. ${ }^{10}$ Moreover, there are several types of research indicating that SGK1 downregulation can inhibit the activity of the NF- $\kappa B$ pathway. ${ }^{11-13}$ Meanwhile, the repression of NF- $\kappa \mathrm{B}$ by curcumin can enhance the antitumor effects of chemotherapeutics in gastric cancer. ${ }^{14}$ Hence, NF-кB blocking is a helpful strategy for tumor suppression via promoting apoptosis and repressing cell growth.

In this study, an increased level of SGK1 was first detected in gastric cancer cells. Based on our results and on previous studies, we posted a hypothesis that SGK1 silencing might suppress the progress of gastric cancer, likely via blocking the NF- $\kappa \mathrm{B}$ signaling pathway. To confirm this hypothesis, we conducted an SGK1silenced model in 2 cell lines to investigate the effect of SGK1 in the progress of gastric carcinoma.

\section{MATERIAL AND METHODS}

\section{Cell Culture and Transfection}

The gastric carcinoma cell lines SNU-1 (Procell, Wuhan, China), NCI-N87 (Procell), MKN45 (FuHeng, Shanghai, China), and the normal gastric epithelial cells GES-1 (FengHui BioLogy, Hunan, China) were cultured in RPMI-1640 medium (31800, Solarbio, China) containing 10\% fetal bovine serum (FBS, SH30084.03, HyClone, USA). AGS cell lines (ZQXZ, Shanghai) were grown in an F12K medium (ZQ-599, ZQXZ) containing 10\% FBS. HGC-27 cell lines (Procell) were grown in an RPMI-1640 medium containing $20 \%$ FBS. The cells were cultured in a controlled environment $\left(5 \% \mathrm{CO}_{2}, 37^{\circ} \mathrm{C}\right)$.

\section{Vector Construction and Cell Transfection}

The sequences of siRNA are listed in Supplementary Table 1. The HGC-27 and NCI-N87 cell lines were transfected with SGK1 siRNAs, or si-NC. SGK1-overexpressed vectors were constructed by inserting the CDS sequence into pcDNA3.1 vectors. To examine the function of miR-15a-5p in regulating SGK1, HGC-27 and NCI-N87 cell lines were also co-transfected with the miR-15a-5p mimic (JTS scientific, Wuhan) or/and SGK1-overexpressed vectors. Blank vectors were used as the negative control. Lipofectamine 3000 reagents (L3000015, Invitrogen, USA) were employed for cell transfection.

\section{qRT-PCR}

TRIpure (RP1001, BioTeke Corporation, China) was used for total RNA or miRNA extraction. Then, total RNA and miRNA were synthesized into cDNA by the SuperScript M-MLV reverse transcriptase (PR6502, BioTeke Corporation) and the miRNA cDNA Synthesis kit (\#B532451, Sangon Biotech, Shanghai), respectively. Finally, the qRT-PCR was conducted according to the protocols.
GAPDH served as a control. The relative level of the specific mRNAs was analyzed using the $2^{-\Delta \Delta C T}$ method. The sequences of the primers are listed in Supplementary Table 2.

\section{Western Blot}

The proteins were abstracted with RIPA (R0010, Solarbio), separated by SDS-polyacrylamide gel system, and electrically transferred to PVDF membranes (IPVH00010, Millipore, USA). After blocking with 5\% fat-free milk (A600669, Sangon) for $1 \mathrm{~h}$, the proteins were incubated at $4{ }^{\circ} \mathrm{C}$ for 18 hours with the following antibodies: SGK1 (1: 400, A1025, ABclonal, China), cyclin D (1: 1000, A19038, ABclonal, China), cyclin E (1: 500, A14225, ABclonal), N-cadherin (1 : 1000, A19083, ABclonal), Vimentin (1 : 1000, AF7013, Affinity, China), caspase-3 (1 : 1000, CST, No. 14220), caspase-9 (1 : 1000, CST, No. 9508), MMP2 (1 : 500, 10373-2-AP, Proteintech), MMP9 (1 : 1000, 10375-2-AP, Proteintech), E-cadherin (1 : 500, A3044, ABclonal), p-ІкB $\alpha$ (1 : 500, AP0707, ABclonal), IкB $\alpha$ (1 : 500, A1187, ABclonal), p65 (1 : 1000, A2547, ABclonal), and p-p65 (1 : 1000, AF2006, Affinity). The next day, the proteins were immuno-blotted with HRP-IgG at $37^{\circ} \mathrm{C}$ for $1 \mathrm{~h}$. The relative protein level was normalized to GAPDH ( $1: 10000$, sc-47778, Santa Cruz). Bands were visualized by a gel image system (WD-9413B, LIU YI, Beijing, China).

\section{Cell Proliferation Assay}

To study the function of SGK1 on cell proliferation, the cells at the density of $5 \times 10^{3}$ cells /well were seeded in a 96-well plate of y13B (LIU YI, Beijing, China; AF2006, Affinity). Vector construction and cell transfection or cells were treated with cisplatin (MB1055, meilunbio, Dalian) at $0,0.25,0.5,1,1.5,2,3,4$, and $6 \mu \mathrm{M}$ after cell transfection. After further growth for different durations, $10 \mu \mathrm{L}$ CCK-8 solution (96992, Sigma, USA) per well was added. After treatment at $37{ }^{\circ} \mathrm{C}$ for $1 \mathrm{~h}$, the absorbance value at $450 \mathrm{~nm}$ was detected by a microplate reader $(800 \mathrm{Ts}$, BioTek, USA).

\section{Cell Cycle and Apoptosis Assay}

Cells $\left(4 \times 10^{5}\right.$ cells/well) were planted in a 6 -well plate. The cell cycle and apoptosis were determined by using the commercial kit (C1052, Beyotime) according to the users' manual.

\section{Wound-healing Assay}

Cells were incubated with $1 \mu \mathrm{g} / \mathrm{mL}$ mitomycin C (M0503, Sigma) for $60 \mathrm{~min}$. Next, the cells were wounded using a $200-\mu \mathrm{L}$ pipette tip and the migration distance was photographed and recorded at $0 \mathrm{~h}$, $24 \mathrm{~h}$, and $48 \mathrm{~h}$.

\section{Invasion Assay}

The transwell invasion assay was conducted to detect the function of SGK1 on cell invasion. Briefly, the upper chamber (3422, Corning) was coated with Matrigel matrix (356234, Corning, USA) for 2 hours at $37^{\circ} \mathrm{C}$. After that, $200 \mu \mathrm{L}$ of cell suspension was added to the upper chamber, and $800 \mu \mathrm{L}$ of medium supplemented with $10 \%$ FBS was added to the bottom chamber. After that, the cells were cultured for 24 hours at $37{ }^{\circ} \mathrm{C}$, fixed with $4 \%$ paraformaldehyde, and next incubated with crystal violet $(0.4 \%, 0528$, Amresco, 
USA) for 5 min. Finally, the cells were photographed and the invasion cell number was counted.

\section{Immunofluorescence Assay}

Firstly, the cells were fixed with $4 \%$ paraformaldehyde at $25{ }^{\circ} \mathrm{C}$ for 15 minutes. Next, the cells were incubated for 30 minutes with Triton X-100 (ST795, Beyotime, China). the nonspecific proteins were then blocked with Normal Goat Serum (SL038, Solarbio, China) for $15 \mathrm{~min}$ at $25^{\circ} \mathrm{C}$. After incubation with the primary antibody p65 (1 : 200, A2547, ABclonal) at $4{ }^{\circ} \mathrm{C}$ for $18 \mathrm{~h}$, the fluorescent antibody was applied and incubated at $25{ }^{\circ} \mathrm{C}$ for 1 hour. Finally, the cell nuclei were counterstained with DAPI (C1002, Beyotime), and the pictures were obtained by a fluorescent microscope (DP73, OLYMPUS, Japan).

\section{Luciferase Reporter Assay}

The interaction between miR-15a-5p and SGK1 was evaluated by the luciferase reporter assay. Briefly, the SGK1 sequence with the targeted site of miR-15a-5p was inserted into the pmirGLO vector (Promega, USA) and named the wt-SGK1-site. Then, the binding site was mutated and named the mut-SGK1-site. After cell transfection, a luciferase detection kit (KGAF040, KeyGen, China) was applied to determine the luciferase activity, according to the manufacturer's instructions.

\section{Statistical Analysis}

The quantitative values were shown as the means \pm SD. Statistical analysis was conducted using GraphPad Prism 8.0 (GraphPad, CA, USA). The qRT-PCR, cell apoptosis assay, and luciferase reporter assay were analyzed with one-way ANOVA. The CCK-8, invasion, and wound-healing data were analyzed by two-way ANOVA. A value of $P<.05$ was identified as statistically significant. Moreover, all data were in a normal distribution, which was tested by the Kolmogorov-Smirnov test $(P>.1)$.

\section{RESULTS}

\section{SGK1 Silencing Inhibited Gastric Cancer Cell Proliferation}

To determine the effect of SGK1 in gastric cancer, we investigated its level in 5 gastric cancer cell lines. Our results revealed that when compared with normal gastric epithelial cells, SGK1 expression was elevated in gastric cancer cells (Figure 1A), indicating that SGK1 might act as an activator in gastric cancer. Hence, we constructed an SGK1-silenced model in 2 gastric cancer cell lines. The knockdown efficiency of SGK1 was confirmed by qRT-PCR and Western blot assays (Figure 1 Band $\mathrm{C}, P<.01$ ). To disclose the effects of SGK1 in gastric cell proliferation, the CCK-8 was first conducted to evaluate cell proliferation. In the SGK1-silenced NCIN87 cells, cell viability was significantly suppressed at $24 \mathrm{~h}, 48 \mathrm{~h}$, and 72 hours $(P<.05)$. In the SGK1-silenced HGC-27 cells, cell proliferation was also prominently repressed (Figure 1D, $P<.01$ ). Moreover, the cell cycle assay exhibited that SGK1 silencing results in a larger numbers of cells in the G1 phase, and to the contrary, fewer cells in the S and G2 phases after SGK1 silencing, than that in the control cells (Figure 1E). Western blot data suggested that the levels of cyclin D and cyclin E were reduced on account of SGK1 depletion (Figure 1F). Overall, we concluded that SGK1 deficiency repressed gastric cancer cell proliferation via mediating cell cycle progression.

SGK1 Deficiency Suppressed Cell Migration and Invasion To determine whether SGK1 enhanced the capacity of gastric cancer cells to migrate and invade, we further conducted wound healing and transwell invasion assays. Our findings demonstrated that SGK1 deficiency led to the significant inhibition of cell migration at 48 hours, and invasion (Figure $2 \mathrm{~A}-\mathrm{D}, P<$ $.01)$. Moreover, the decreased production of MMP9 and MMP2 were observed in SGK1-silenced NCI-N87 and HGC-27 cells (Figure 2E). Likewise, knockdown of SGK1 enhanced E-cadherin expression whereas it decreased N-cadherin expression (Figure 2F). Collectively, we revealed that SGK1 downregulation abrogated the cell migration and invasion activities of gastric carcinoma cells.

\section{SGK1 Deficiency Enhanced Cisplatin Sensitivity of Gastric Carcinoma Cells}

To assess the effect of SGK1 on cisplatin sensitivity, the SGK1 down-regulated cells were treated with cisplatin. Our CCK-8 assay showed that SGK1-silenced cells exhibited lessened cell viability relative to that in control cells after cisplatin treatment at different concentrations $(0,0.25,0.5,1,1.5,2,3,4$, and $6 \mu \mathrm{M})$ (Figure $3 \mathrm{~A}, P<.01$ ). The IC50 in the control group was calculated based on the CCK-8 results in Figure 3A. To investigate whether knockdown of SGK1 could promote the cisplatin sensitivity, a low-dose cisplatin $(1.5 \mu \mathrm{M}$, a quarter of the IC50 of the control cells, Figure S1) was chosen for the subsequent experiments. Compared with the negative control, SGK1 deficiency significantly promoted cell apoptosis in SGK1-silenced cells after cisplatin treatment (Figure 3B). Furthermore, the elevated production of active caspase- 3 and caspase- 9 were observed after cisplatin or si-SGK1 treatment. When cisplatin and si-SGK1 were used in combination, the production of active caspase- 3 and caspase-9 was found to be further upregulated (Figure 3C). Collectively, our results showed that SGK1 deficiency enhanced cisplatin sensitivity of gastric cancer cell lines.

SGK1 Silencing Repressed the NF-кB Signaling Pathway Mechanically, we detected the levels of p65, p-p65, IкB $\alpha$, and $\mathrm{p}-\mathrm{I} \kappa \mathrm{B} \alpha$. The immunofluorescence staining results showed that fewer p65-positive proteins were stained in the nucleus after SGK1 silencing, indicating that SGK1 loss of function repressed the nucleus translocation of p65 (Figure 4A). Consistent with the findings of immunofluorescence staining, Western blot results exhibited that SGK1 deficiency decreased the production of p-p65 and $\mathrm{p}-\mathrm{I} \kappa \mathrm{B} \alpha$, suggesting an inhibitory effect of SGK1 silencing on the NF- $\kappa$ B pathway (Figure 4B). Taken together, these results affirmed that SGK1 accelerated gastric cancer deterioration, likely via regulating the NF- $\mathrm{KB}$ signaling pathway. 
A
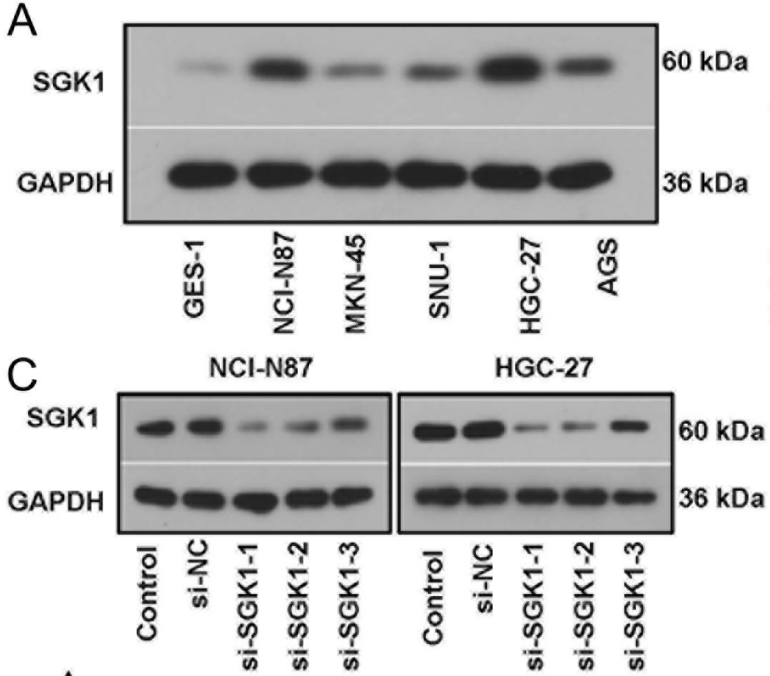

$\mathrm{E}$

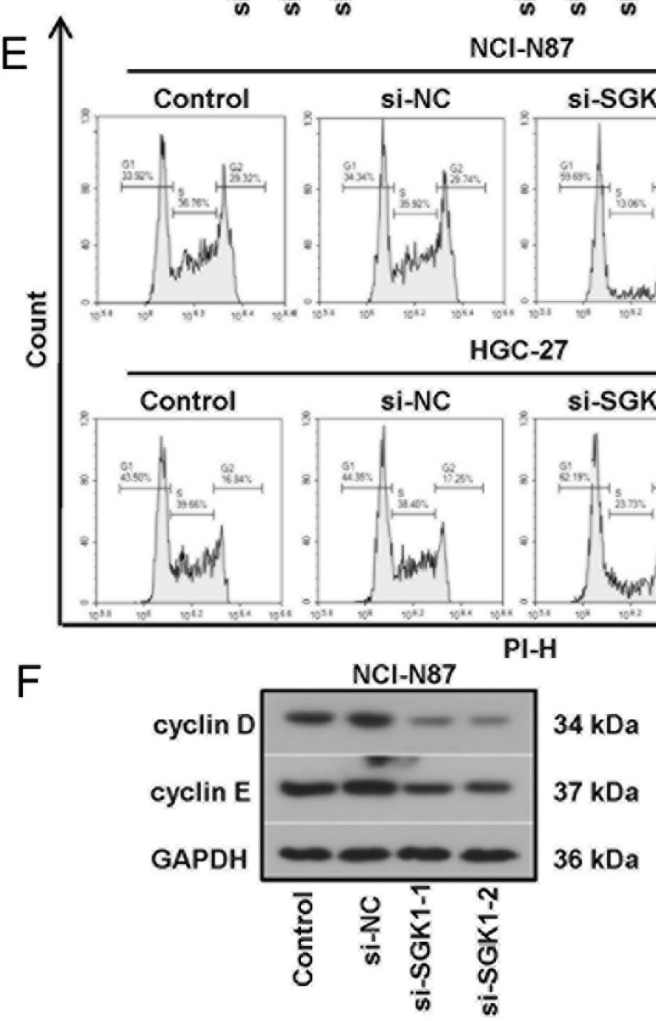

HGC-27

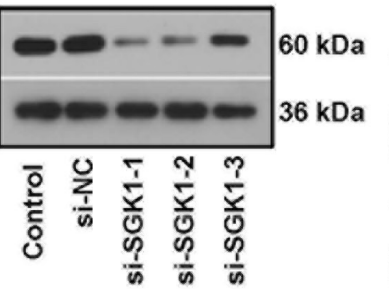

B Control $\square$ si-SGK1-1 si-SGK1-3

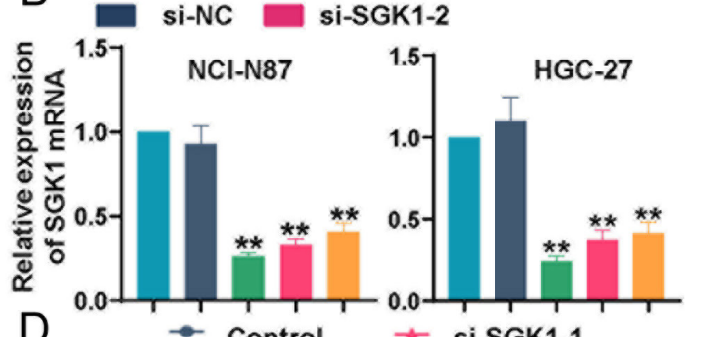

D

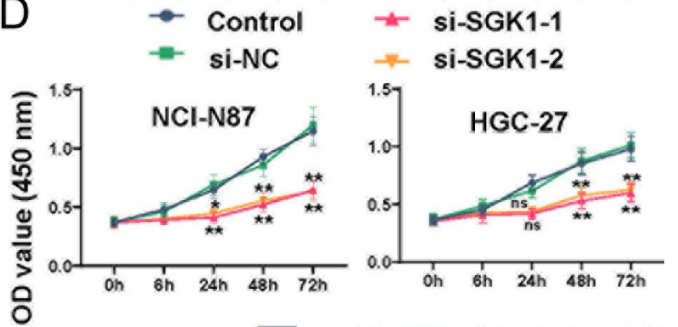


A
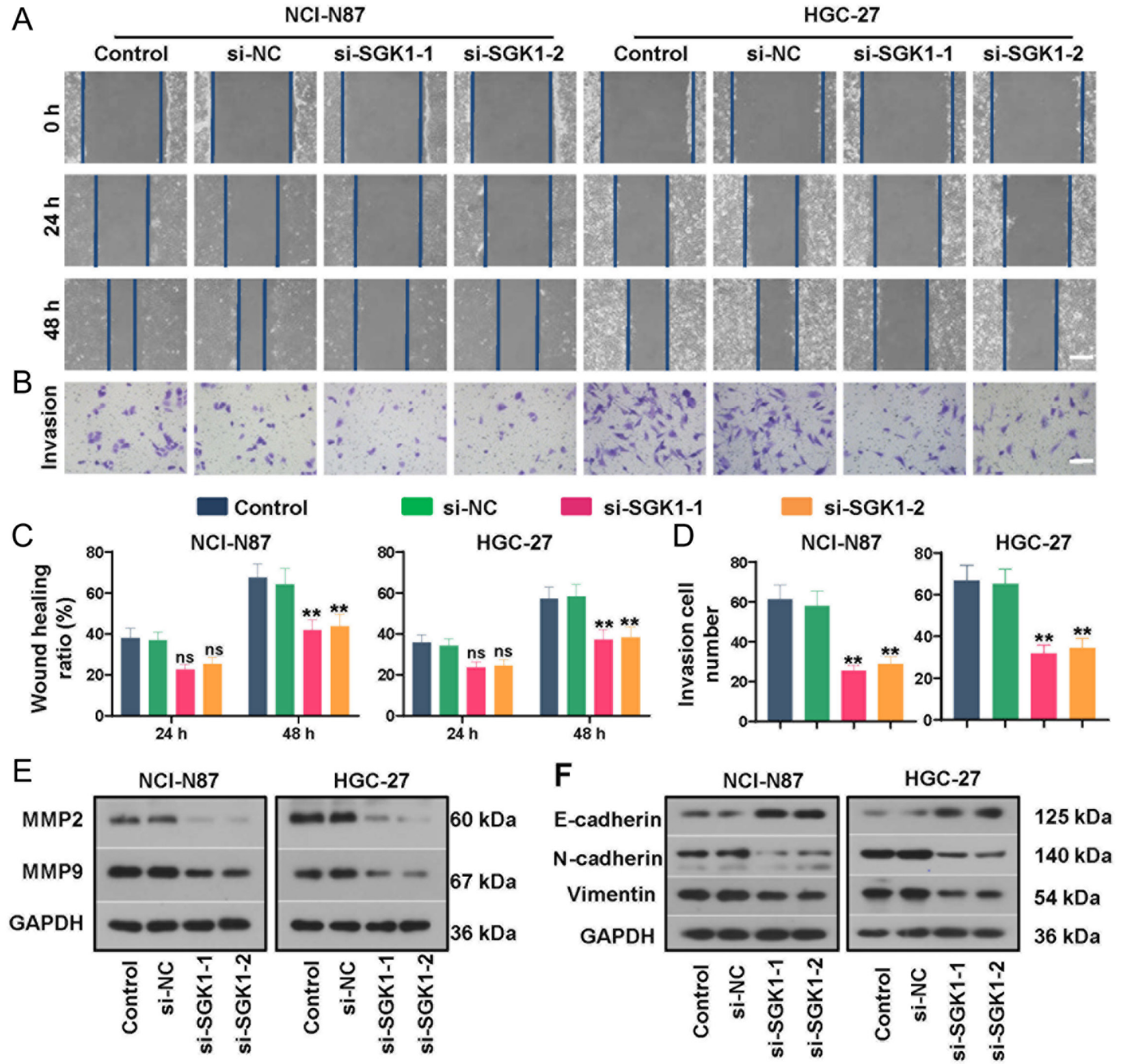

$125 \mathrm{kDa}$

$140 \mathrm{kDa}$

$54 \mathrm{kDa}$

$36 \mathrm{kDa}$

F. 2 (A-F). SGK1 deficiency suppressed migration and invasion activities of gastric carcinoma cells. SGK1 loss of function blocked (A) gastric carcinoma cell migration and (B) invasion. (C, D) Quantitative data of cell migration and invasion. The levels of (E) MMP-2 and MMP-9 and (F) E-cadherin, N-cadherin, and Vimentin were detected by Western blot. ${ }^{* *} P<.01$ compared with NC siRNA. Scale bar $=200 \mu \mathrm{m}$ in $(A)$, Scale bar $=100 \mu \mathrm{m}$ in $(B)$.

\section{DISCUSSION}

As treatment strategies are constantly evolving, chemotherapy, such as platinum-based chemotherapy containing cisplatin and oxaliplatin, has become an effective method for the treatment of advanced gastric cancer. ${ }^{15,16}$ However, among patients undergoing treatment, there are obviously individual differences in response rates and survival rates, and drug resistance limits the productiveness of cancer chemotherapy and constitutes a major obstacle in clinical treatment. ${ }^{17}$ Therefore, enhancing the chemotherapy sensitivity of gastric cancer cells is essential for gastric cancer therapy.
In our study, we have revealed that SGK1 deficiency improved the sensitivity of gastric cancer cells to cisplatin, alleviating the deterioration of gastric carcinoma.

Recent researches have shown that SGK1 serves as an activator in tumorigenesis. For example, SGK1 enhances the survival, invasiveness, and adhesiveness of colorectal carcinoma cells. ${ }^{5}$ SGK1 presumably regulates the survival of kidney cancer cells and cholangiocarcinoma cells. ${ }^{18-20}$ In our study, we found that SGK1 deficiency suppressed the proliferation, invasion, and migration of gastric cancer cells. Consistently, Lang et al have 

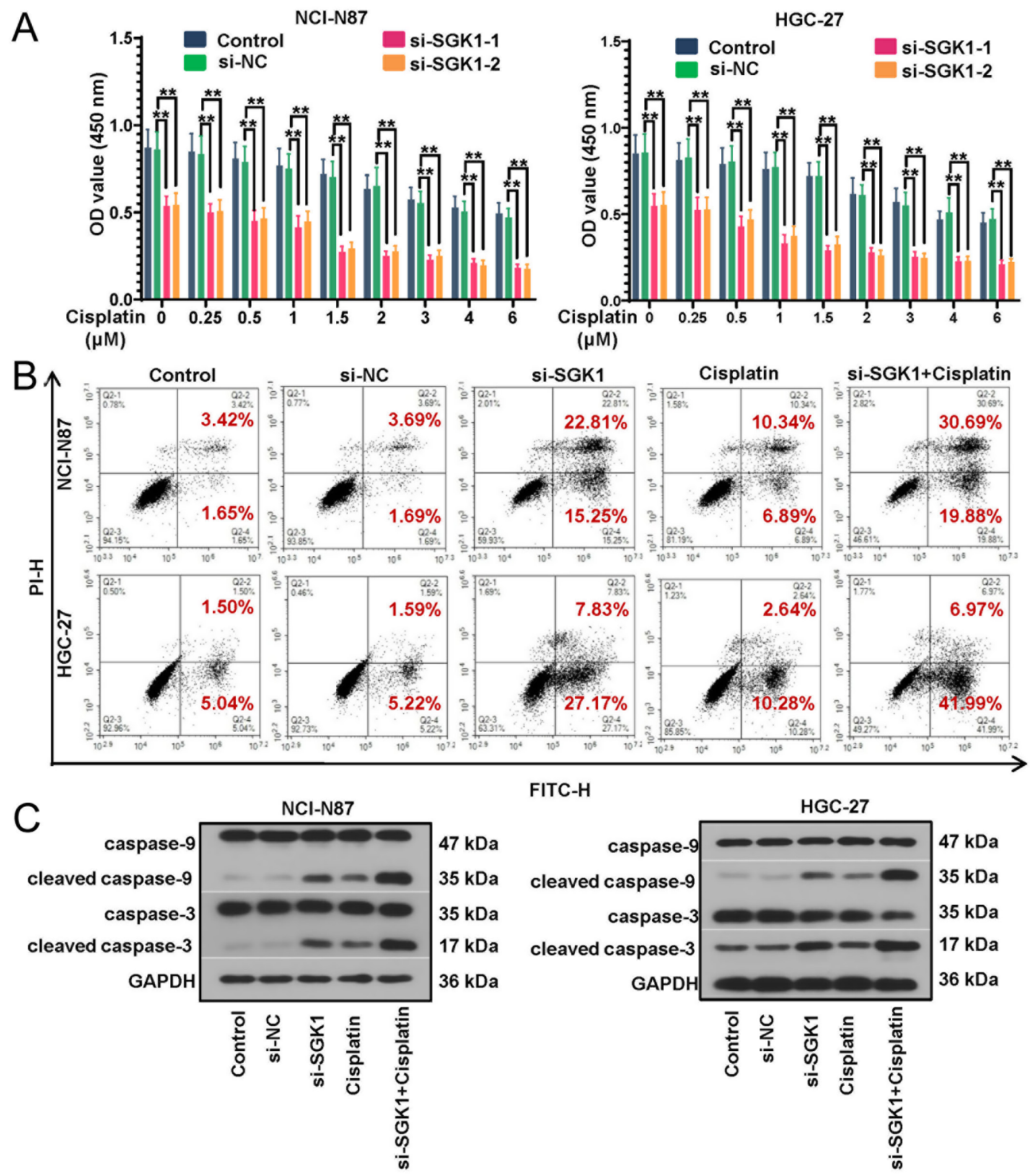

FIG. 3. (A-C). SGK1 deficiency promoted the chemosensitivity of gastric carcinoma cells. (A) The cell viability of SGK1-silenced cells was administrated with different concentrations of cisplatin for $48 \mathrm{~h}$. (B) The cell apoptosis (with or without SGK1 deficiency) after cisplatin (1.5 $\mu \mathrm{M})$ treatment. (C) The expression of caspases in cells. ${ }^{* *} P<.01$, compared with NC si-RNA.

expounded that SGK1 promotes the adhesion of MDCK cells to fibronectin and inhibits chemotherapy-induced apoptosis, which exhibits an ability to confer cell survival. ${ }^{18,20}$ Zhang et al have declared that SGK1 exerts the antiapoptotic effect in breast cancer cells, in part via regulating NF- $\mathrm{BB}$ signaling. ${ }^{21}$ Additionally, SGK1 is implicated in chemoresistance. ${ }^{22}$ For instance, tumors with SGK1 gain of function are resistant to paclitaxel-dependent cell death. ${ }^{23}$ Our study also showed that SGK1 deficiency inhibited gastric cancer cell proliferation and promoted apoptosis after cisplatin treatment, indicating that downregulation of SGK1 improved chemotherapy sensitivity of gastric cancer cells to cisplatin. 
A
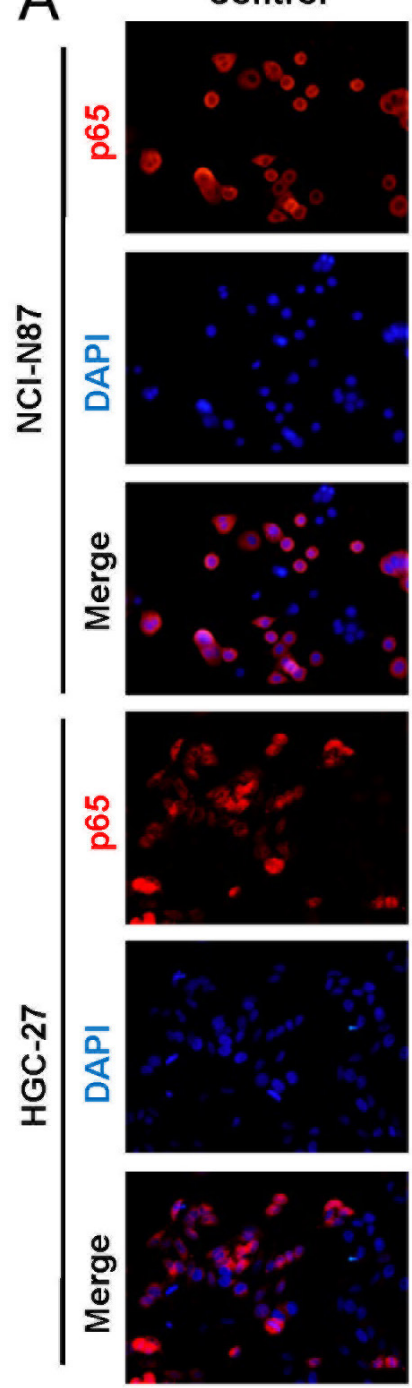

si-NC
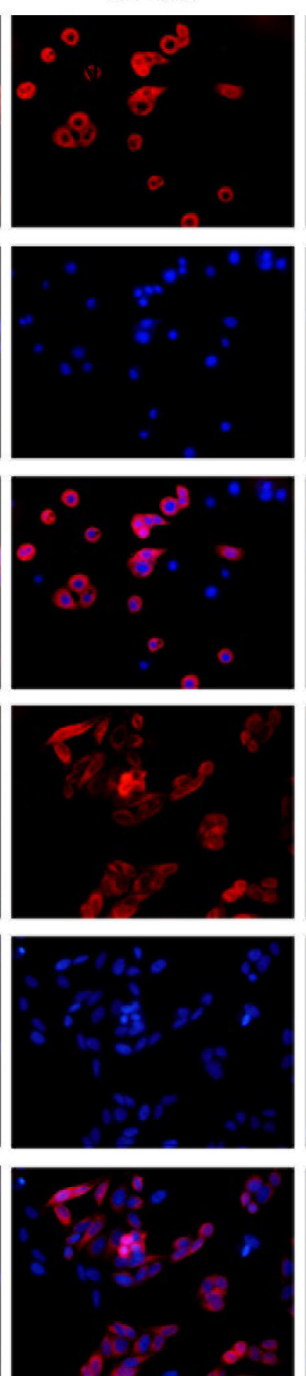

si-SGK1
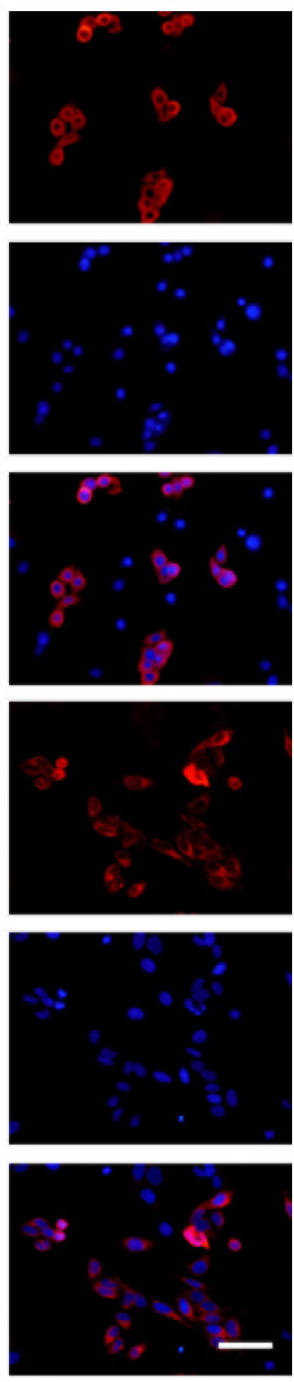

B
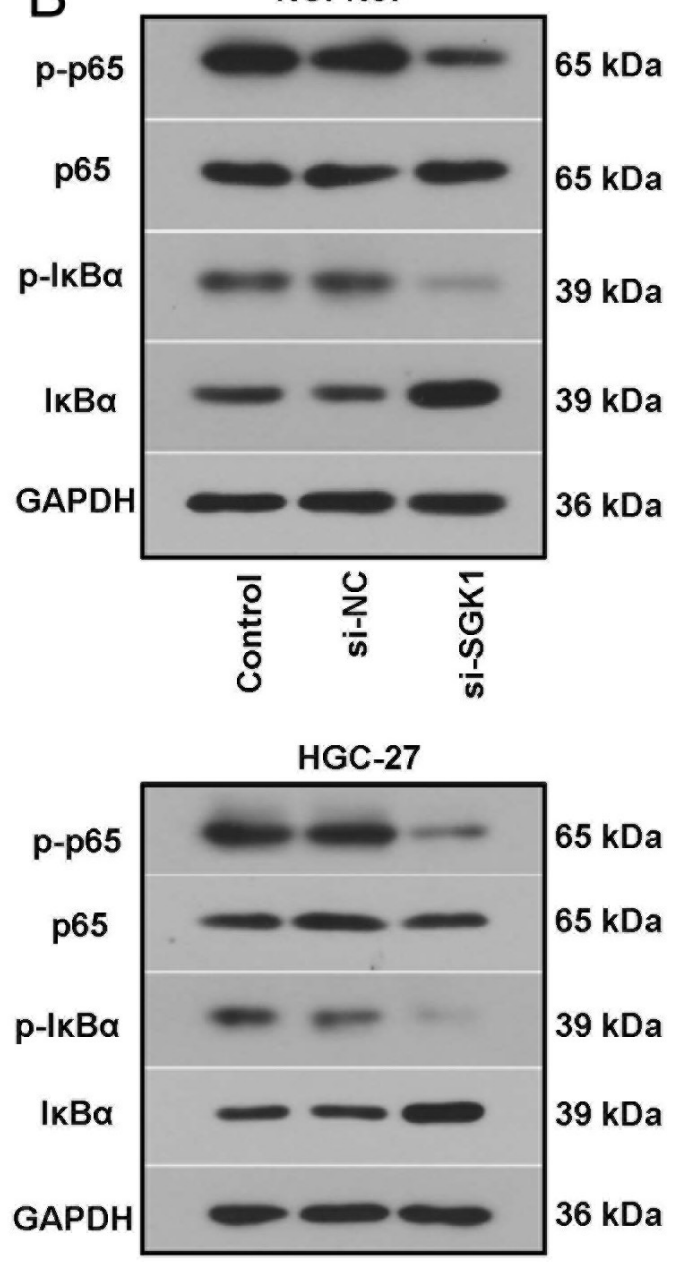

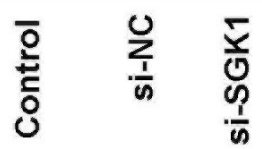

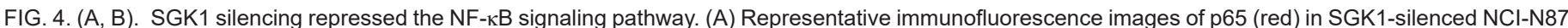

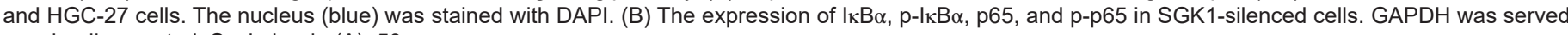
as a loading control. Scale bar in (A): $50 \mu \mathrm{m}$.

Furthermore, our study stated that SGK1 loss of function obviously decreased the phosphorylation of p 65 and $\mathrm{I} \kappa \mathrm{B}$, indicating the downregulation of $\mathrm{NF}-\kappa \mathrm{B}$. In line with our results, it is reported in hematological and epithelial malignancies that suppression of NF- $\kappa \mathrm{B}$ leads to enhanced apoptosis. ${ }^{24-26}$ In addition, NF- $\kappa \mathrm{B}$ activation in tumor cells can promote the production of new vascular and metastatic factors, causing drug resistance and reduced effectiveness of therapy. ${ }^{27}$ It is noteworthy that stimulating upstream genes of NF- $\kappa \mathrm{B}$ exhibits a promoting effect in cancer resistance. ${ }^{28} \mathrm{~A}$ previous study has shown that SGK1 can act as an upstream activator of the NF- $\mathrm{KB}$ pathway, indicating that SGK1 may promote cancer resistance via upregulating the NF- $\mathrm{kB}$ pathway. ${ }^{11,13}$ Interestingly, we also showed that SGK1 might exert the inhibitory effect in gastric cancer via being targeted by miR-15a-5p. Existing research has indicated that miR-15a-5p level is reduced in cisplatin-resistant gastric cancer cells, which participates in the prognosis of patients with adjuvant chemotherapy. ${ }^{29}$ Another research has implicated that miR-15a-5p inhibition reduces the cisplatin sensitivity of carcinoma cells. ${ }^{30}$ However, the regulatory effect of miR-15a-5p by targeting SGK1 in gastric cancer needs further exploration.

In a word, these data indicated that downregulation of SGK1 promoted the chemosensitivity of gastric cancer to cisplatin and alleviated the deterioration of gastric carcinoma by suppressing the NF-кB pathway (Figure 6). Thus, SGK1 might become a prospective target for future gastric cancer therapy. 
A SGK1 3' UTR 5' GCUUAAAGAAAGCAUUGCUGCUA C 후 Has-miR-15a-5p GUGUUUGGUAAUACACGACGAU

B

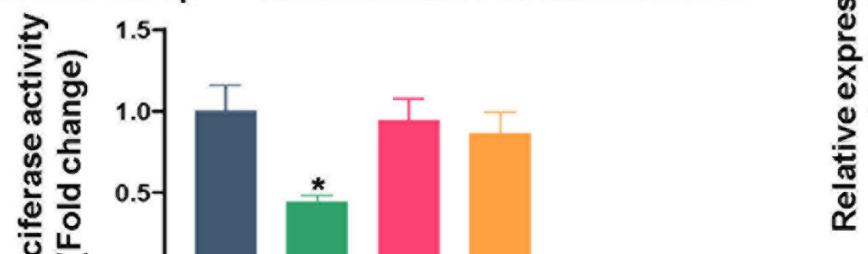

D

\begin{tabular}{lccc}
\hline NC mimic & NC mimic & miR-15a-5p & miR-15a-5p \\
+ vector & + SGK1 & mimic+ vector & mimic+SGK1
\end{tabular}
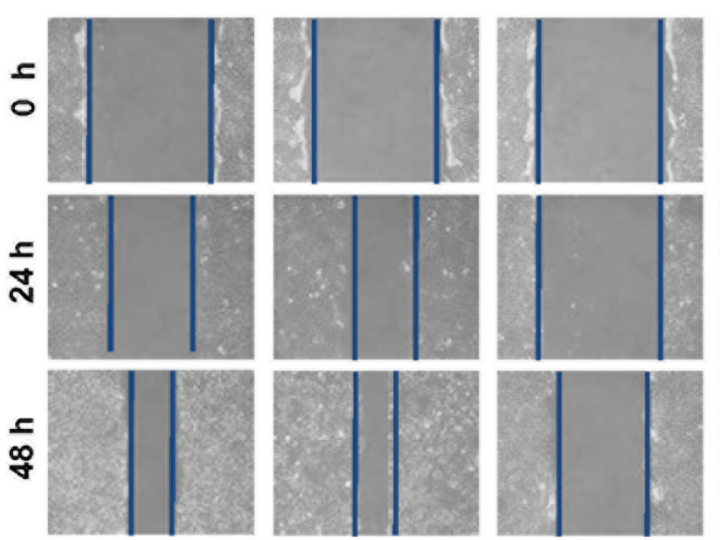

HGC-27
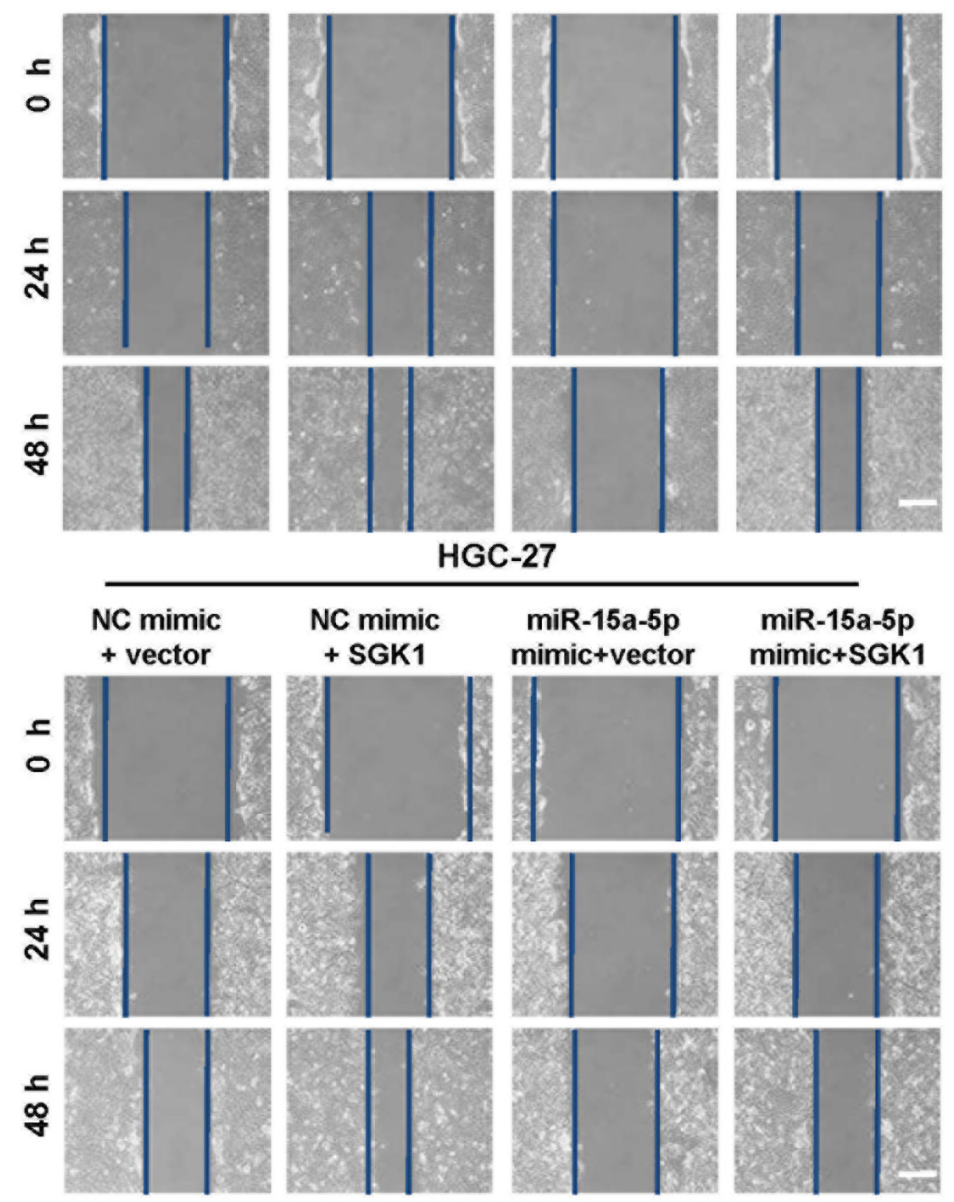
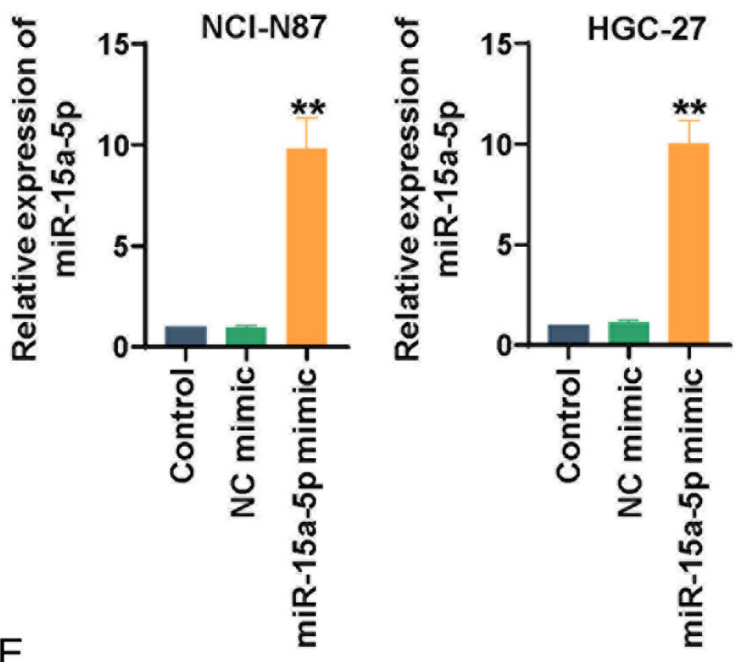

E

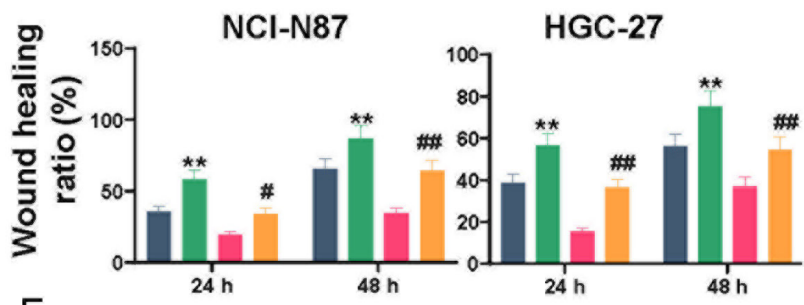

$\mathrm{F}$

$\mathrm{NC}$ mimic + vector

NC mimic+SGK1

miR-15a-5p mimic+ vector

miR-15a-5p mimic+SGK1
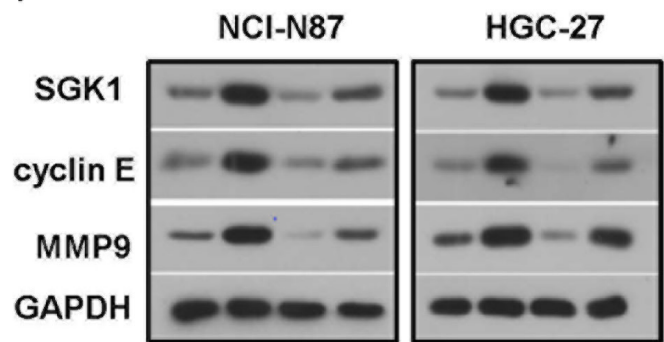

$60 \mathrm{kDa}$

$47 \mathrm{kDa}$

$67 \mathrm{kDa}$

$36 \mathrm{kDa}$

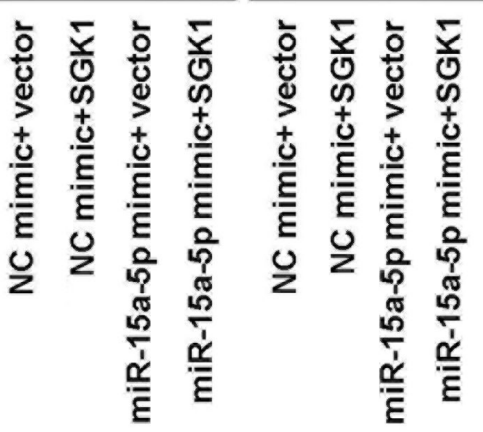

FIG. 5. (A-F). SGK1 targeted by miR-15a-5p promoted gastric cancer cell migration. (A) The binding site of miR-15a-5p on the 3'UTR of SGK1. (B) The luciferase activities in HGC-27 cells. ${ }^{*} P<.05$, compared with SGK1 3'UTR $w t+N C$ mimic. (C) The miR-15a-5p production in 2 gastric carcinoma cells lines ${ }^{* *} P<.01$, compared with NC mimic. (D, E) The cell migration of gastric carcinoma cells (with or without miR-15a-5p mimic or/and SGK1 overexpression transfected). Scale bar: $200 \mu \mathrm{m}$. One-way ANOVA, ${ }^{* *} P<.01$, compared with NC mimic + vector; ${ }^{\#} P<.05,{ }^{\#} P<.01$, compared with miR-15a-5p + vector. (F) The protein levels of SGK1, cyclin E, and MMP9 (with or without miR-15a-5p mimic or/and SGK1 overexpression transfected). GAPDH served as a loading control. Scale bar in (D): $200 \mu \mathrm{m}$. 


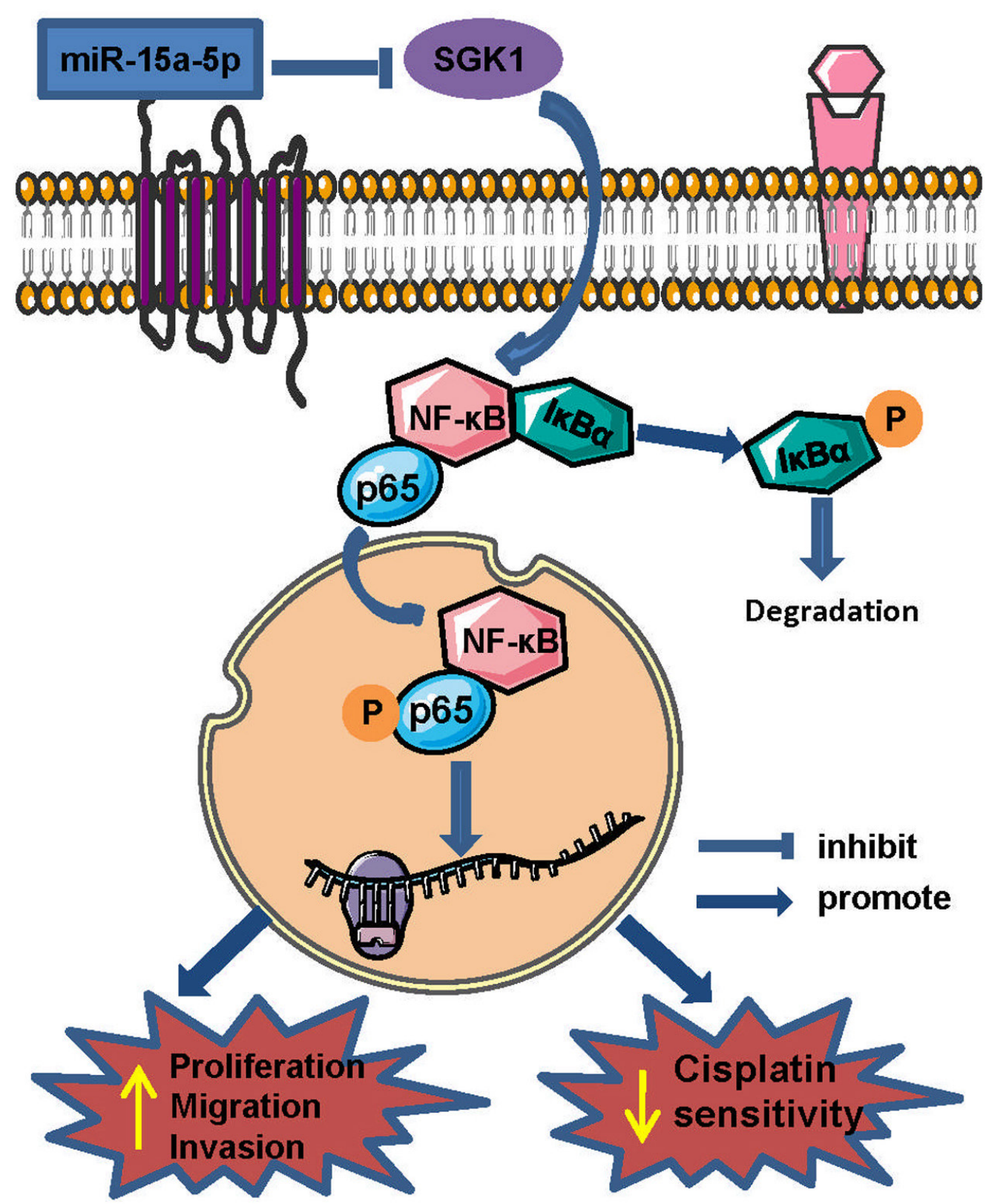

FIG. 6. Schematic diagram of the mechanism of SGK1 in promoting the malignant behavior and lessening the cisplatin sensitivity of gastric cancer cells.

Ethics Committee Approval: N/A.

Patient Consent for Publication: N/A.

Data sharing Statement: The data that support the findings of this study are available from the corresponding author upon reasonable request.

Author Contributions: Concept - J.Z.; Design - J.Z.; Supervision - J.Z.; Data Collection and Processing - J.Z., W.L, L.Y., W.F.; Analysis and/or Interpretation - B.C., Q.M.; Figure Organization - X.G.; Writing - J.Z., X.C.

Conflict of Interest: The authors have no conflicts of interest to declare.

Funding: The authors declared that this study had received no financial support.

\section{REFERENCES}

1. Rahman R, Asombang AW, Ibdah JA. Characteristics of gastric cancer in Asia. World J Gastroenterol. 2014;20(16):4483-4490. [CrossRef]

2. Zhang D, Fan D. Multidrug resistance in gastric cancer: recent research advances and ongoing therapeutic challenges. Expert Rev Anticancer Ther. 2007;7(10):1369-1378. [CrossRef]

3. Eghdami A, Ostovar R, Jafari A, et al. Economic burden of gastric cancer: A case of Iran. Cancer Control. 2019;26(1):1073274819837185. [CrossRef]

4. Sakamoto J, Matsui T, Kodera Y. Paclitaxel chemotherapy for the treatment of gastric cancer. Gastric Cancer. 2009;12(2):69-78. [CrossRef]

5. Lang F, Perrotti N, Stournaras C. Colorectal carcinoma cells--regulation of survival and growth by SGK1. Int J Biochem Cell Biol. 2010;42(10):1571-1575. [CrossRef] 
6. Szmulewitz RZ, Chung E, Al-Ahmadie H, et al. Serum/glucocorticoid-regulated kinase 1 expression in primary human prostate cancers. Prostate. 2012;72(2):157164. [CrossRef]

7. Zhu J, Zhang R, Yang D, et al. Knockdown of Long Non-Coding RNA XIST inhibited doxorubicin resistance in colorectal cancer by upregulation of miR-124 and downregulation of SGK1. Cell Physiol Biochem. 2018;51(1):113-128. [CrossRef]

8. D'Antona L, Dattilo V, Catalogna G, Scumaci D, Fiumara CV, Musumeci F, et al. In preclinical model of ovarian cancer, the SGK1 inhibitor SI113 counteracts the development of paclitaxel resistance and restores drug sensitivity. Transl Oncol. 2019;12(8):1045-1055.

9. Yao Y, Jiang Q, Jiang L, et al. Lnc-SGK1 induced by Helicobacter pylori infection and highsalt diet promote Th2 and Th17 differentiation in human gastric cancer by SGK1/Jun B signaling. Oncotarget. 2016;7(15):20549-20560. [CrossRef]

10. Mortezaee K, Najafi M, Farhood B, et al. NF- $\mathrm{kB}$ targeting for overcoming tumor resistance and normal tissues toxicity. J Cell Physiol. 2019;234(10):17187-17204. [CrossRef]

11. Lang F, Pelzl L, Hauser S, et al. To die or not to die SGK1-sensitive ORAI/STIM in cell survival. Cell Calcium. 2018;74:29-34. [CrossRef]

12. Borst $\mathrm{O}$, Schmidt EM, Münzer $\mathrm{P}$, et al. The serum- and glucocorticoid-inducible kinase 1 (SGK1) influences platelet calcium signaling and function by regulation of Orai1 expression in megakaryocytes. Blood. 2012;119(1):251-261. [CrossRef]

13. Yu W, Honisch S, Schmidt S, et al. Chorein-sensitive Orail expression and store operated $\mathrm{Ca} 2+$ entry in rhabdomyosarcoma cells. Cell Physiol Biochem. 2016;40(5):1141-1152. [CrossRef]

14. Yu LL, Wu JG, Dai N, Yu HG, Si JM. Curcumin reverses chemoresistance of human gastric cancer cells by downregulating the NF- $\mathrm{kB}$ transcription factor. Oncol Rep. 2011;26(5):1197-1203. [CrossRef]

15. Cunningham D, Allum WH, Stenning SP, et al. Perioperative chemotherapy versus surgery alone for resectable gastroesophageal cancer. $N$ Engl J Med. 2006;355(1):1120. [CrossRef]

16. Subhash VV, Tan SH, Tan WL, et al. GTSE1 expression represses apoptotic signaling and confers cisplatin resistance in gastric cancer cells. BMC Cancer. 2015;15:550. [CrossRef]

17. Metzger R, Bollschweiler E, Hölscher AH, Warnecke-Eberz U. ERCC1: impact in multimodality treatment of upper gastrointestinal cancer. Future Oncol. 2010;6(11):1735-1749. [CrossRef]
18. Lang F, Böhmer C, Palmada M, et al. (Patho)physiological significance of the serumand glucocorticoid-inducible kinase isoforms. Physiol Rev. 2006;86(4):1151-1178. [CrossRef]

19. Amato R, D'Antona L, Porciatti G, et al. Sgk1 activates MDM2-dependent p53 degradation and affects cell proliferation, survival, and differentiation. J Mol Med (Berl). 2009;87(12):1221-1239. [CrossRef]

20. Lang F, Artunc F, Vallon V. The physiological impact of the serum and glucocorticoidinducible kinase SGK1. Curr Opin Nephrol Hypertens. 2009;18(5):439-448. [CrossRef]

21. Zhang L, Cui R, Cheng X, Du J. Antiapoptotic effect of serum and glucocorticoidinducible protein kinase is mediated by novel mechanism activating I $\{$ kappa $\} \mathrm{B}$ kinase. Cancer Res. 2005;65(2):457-464.

22. Talarico C, Dattilo V, D'Antona L, et al. SGK1, the new player in the game of resistance: chemo-radio molecular target and strategy for inhibition. Cell Physiol Biochem. 2016;39(5):1863-1876. [CrossRef]

23. Amato R, Scumaci D, D'Antona L, et al. Sgk1 enhances RANBP1 transcript levels and decreases Taxol sensitivity in RKO colon carcinoma cells. Oncogene. 2013;32(38):4572-4578. [CrossRef]

24. Kim HJ, Hawke N, Baldwin AS. NF-kappaB and IKK as therapeutic targets in cancer Cell Death Differ. 2006;13(5):738-747. [CrossRef]

25. Orlowski RZ, Baldwin AS, Jr. NF-kappaB as a therapeutic target in cancer. Trends Mol Med. 2002;8(8):385-389. [CrossRef]

26. Ravi R, Bedi A. NF-kappaB in cancer-a friend turned foe. Drug Resist Updat 2004;7(1):53-67. [CrossRef]

27. Nguyen CH, Senfter D, Basilio J, et al. NF- $\mathrm{kB}$ contributes to MMP1 expression in breast cancer spheroids causing paracrine PAR1 activation and disintegrations in the lymph endothelial barrier in vitro. Oncotarget. 2015;6(36):39262-39275. [CrossRef]

28. Gallardo-Pérez JC, Espinosa M, Ceballos-Cancino G, et al. NF-kappa B is required for the development of tumor spheroids. J Cell Biochem. 2009;108(1):169-180. [CrossRef]

29. Song J, Yin J, Bai Z, et al. The profile of serum microRNAs predicts prognosis for resected gastric cancer patients receiving platinum-based chemotherapy. Dig Dis Sci. 2017;62(5):1223-1234. [CrossRef]

30. Pouliot LM, Chen YC, Bai J, et al. Cisplatin sensitivity mediated by WEE1 and CHK1 is mediated by miR-155 and the miR-15 family. Cancer Res. 2012;72(22):5945-5955. [CrossRef] 


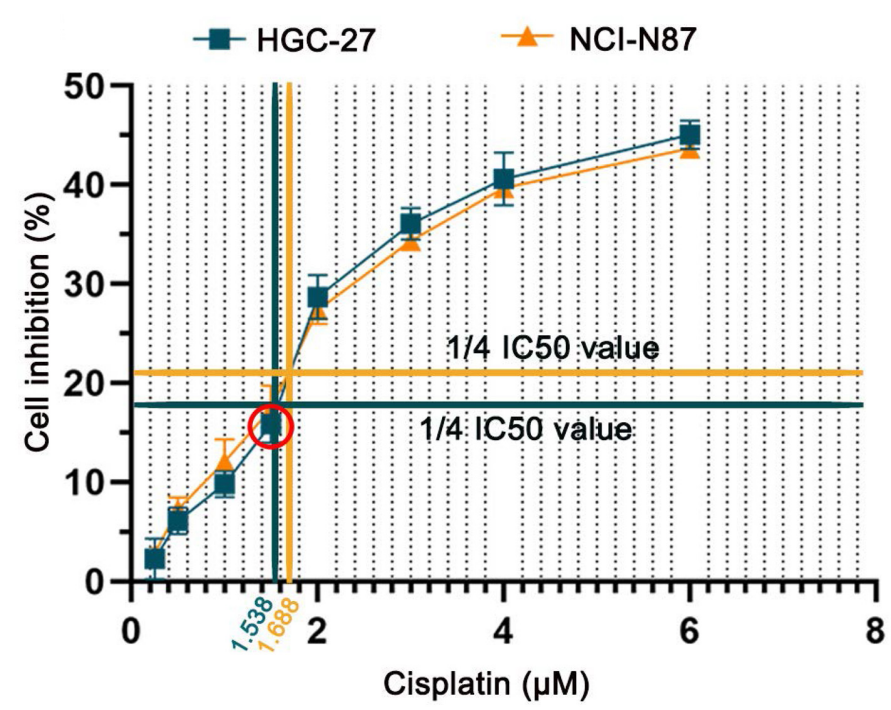

SUPPLEMENTARY FIG. 1. The cell inhibition of NCI-N87 cells and HGC-27 cells in the control group treated with various concentrations $(0,0.25,0.5,1,1.5$ $2,3,4$, and $6 \mu \mathrm{M}$ ) of cisplatin for 48 hours. To investigate whether knockdown of SGK1 could promote the cisplatin sensitivity, a low-dose cisplatin (1.5 $\mu \mathrm{M}$, a quarter of the IC50 of the control cells) was chosen for the subsequent experiments.

SUPPLEMENTARY TABLE 1 . The Sequences of siRNA

Sequences $\left(5^{\prime}-3^{\prime}\right)$

\begin{tabular}{lcc}
\cline { 2 - 3 } Name & Sense & Antisense \\
\hline SGK1 siRNA-1 (si-SGK1) & cguccaauccucaugcuaatt & uuagcaugaggauuggacgtt \\
SGK2 siRNA-2 (si-SGK2) & cugaaauagccagugccuutt & aaggcacuggcuauuucagtt \\
SGK3 siRNA-3 (si-SGK3) & gcggaauguucuguugaag & cuucaacagaacauuccgc \\
Negative control siRNA (si-NC) & uucuccgaacgugucacgutt & acgugacacguucggagaatt \\
\hline
\end{tabular}

SUPPLEMENTARY TABLE 2. The Sequences of the Primers

Sequences $\left(5^{\prime}-3^{\prime}\right)$

\begin{tabular}{lcc} 
Name & Sense & Antisense \\
\hline SGK1 & aggactgtggactggtggtg \\
GAPDH & gacctgactgccgtctag & gaggcttgttcagaatgttgtc \\
aggagtgggtgtcgctgt
\end{tabular}

